\title{
The Development of Spatial Circularity Discourse in Japan: Ecomodernist, Territorialised, or Both? The Story of Onomichi's Wastescapes
}

\author{
Wendy Wuyts ${ }^{1}$ (D) Marjan Marjanović ${ }^{2}$ (D)
}

Received: 31 August 2021 / Accepted: 27 December 2021

(c) The Author(s) 2022

\begin{abstract}
Globally, many national, regional, and urban governments are facilitating circular economy transitions through various pathways. The European Union and China have spearheaded the worldwide shift towards circularity by adopting primarily ecomodernist and technocratic approaches. However, the relevant literature has highlighted the need to integrate conceptualisations of circularity that are more politically and spatially embedded to better suit the local contexts and actual social needs of specific populations. In this paper, we therefore argue that the Japanese approach to circular practices exemplifies a place-bound and just pathway and offers a potential alternative to the European and Chinese methods. Accordingly, we first trace the historical roots of spatial circularity in Japan and then articulate some contemporary circular concepts. Next, we present a detailed analysis of wastescapes in the city of Onomichi to demonstrate through the lived experiences of its citizens that the rather orthodox understandings of circularity that permeate Japanese discourse on circularity coexist with alternative considerations that promote human interactions with nonhuman nature, acknowledge spatial ranges of operations, and value traditional knowledge.
\end{abstract}

Keywords Circular economy $\cdot$ Lived experiences $\cdot$ Sociotechnical imaginaries $\cdot$ Spatial planning $\cdot$ Territorial approach $\cdot$ Vacant housing

\section{Introduction}

During the past decade, governments of many cities, regions, and countries across the globe increasingly began to transition towards circularity [1-3]. Cities, in particular, are locations with solid potentials for circular transitions due to their dense concentration of resources and stakeholders [4]. The circular economy (CE) is an economic model that offers novel practices, narratives, and strategies to address sustainability issues [2, 5], but

Wendy Wuyts

wendy.wuyts@ntnu.no

1 Department of Manufacturing and Civil Engineering, Norwegian University of Science and Technology, Gjøvik, Norway

2 School of Planning, University College London, London, UK 
its principles and roots are not new. The CE is a broad concept with global roots, some of which are hundreds or even thousands of years old, as shown by various researchers [6, 7]. Some concepts familiar to CE experts, such as industrial symbiosis and waste as food, were first mentioned a hundred years ago [7-9]. The current discourses of circularity stem from different political contexts; however, the literature often discusses Chinese and (northwestern) European versions of CE [10]. Circularity has hundreds of definitions [5], which, in a narrow sense, share the vision of retaining the value of materials for as long as possible in a society. This can be done through different strategies, including narrowing, closing, and impeding material (and other resource) loops [11].

The concept of circularity offers a promising solution to address the problems of waste generation, threats to the survival of ecosystems, and resource consumption $[1,2,12]$.

The objective of this paper is to highlight the need for a territorial approach, i.e. a CE that facilitates different pathways adapted to local contexts (the needs of local people, local assets, and local resources) $[13,14]$. Many researchers, mainly from the fields of geography and urban planning, call for a territorial approach to circular economy discourse and planning [4] and investigate spatial requirements or space as a resource $[13,15]$. This brings us to the first research question: What does a territorial approach mean and where is this critique coming from?To answer it, we draw on the grounded work of Geddes [16-18] and Magnaghi [19] and briefly explain the integration of circularity with territorialism and regionalism.

The second research question concerns whether a territorial approach can outmanoeuvre the global tendencies of a concentrated focus on efficiency and economic growth, which often negatively impacts values such as caring for the greater well-being of human and nonhuman nature. Various researchers suggest that a circular economy is not feasible within a political economy of growth. Instead, it is more likely established in a political economy of care and cooperation, i.e. a political economy of degrowth [20]. This might be in contrast with ecomodernism [21], which trusts in the ability of technology and economic growth to address societal challenges and enable circularity. The risk is that this technocratic emphasis might lead to negative social impacts and bring harm from the political and democratic perspective. Please refer to [22] to read the criticism on the ecomodernist trend in circularity research. In the "Methodology and Materials" section, we briefly explain the ecomodernist and technocratic conceptualisations of circularity in the EU and China, as these two regions appear to have paved the road for circularity in recent decades. By doing so, we hope to explain the differences between a territorial and deterritorialised approach and why we consider ecomodernist and technocratic circularity deterriorialised approaches. The European Union and China's policies and indicators comprise ecomodernist and technocratic approaches [22] that might hinder the spatial integrations of circular urban ecosystems and local complexities, leading to uneven distributions of resources and benefits.

This paper then moves away from the frequently highlighted territories of the EU and China and examines whether Japan can demonstrate a third way, especially as spatial forms of circularity in China (industrial symbiosis) are based on Japanese programs.

Although the sound material-cycle society concept can be considered the Japanese version of circularity [23] and seems to be ecomodernist, Japan has also implemented concepts and programs emphasizing the territorial approach, such as ecotown planning, which it began in 1997, and the circulating and ecological sphere (CES), which commenced in 2018. This study's interest lies in the political and spatial dimension of the 'Japanese way'.. In the "A Territorial Approach to Circularity Discourse and Planning" section, we trace the historical roots of spatial circularity and its interpretations in Japan before presenting some contemporary circular concepts in the "Results" section. The third research question is as 
follows: to what extent do the Japanese concepts and programs depart from the ecomodernist and technocratic approaches to circularity to promote a territorial approach that celebrates conviviality? Although previous research has included a comparative study on CE development in Japan, its focus was mostly on national level policies [24] and not on the complexity of what CE means on 'the ground'. More studies of lived experiences and discourse in Japan can address the diversity gap and highlight the political (economy) and cultural preconditions for the interpretation and development of circularity. Hence, we provide an interesting case study on the town of Onomichi in the "Discussion" section to illustrate how localised CE approaches are taken regarding a place in transition by utilizing wasteas-food concepts. As our own stance extols place-based care economies, as addressed by Bauwens [20], we believe it is important to show -by describing lived experiences- what circularity in such a political economy can mean locally. The final research concern is how keeping economic operations small scale, localised, and spatialised to serve primary community needs and work with existing traditions and features can contribute to a more viable circular economy.. In the "Discussion" section, we reflect on our findings and debate whether the example of Japan offers an alternative way to conceptualise circularity or if it is closer to the EU and Chinese approaches to provide questions for future research. The "Conclusion" section concludes the study by describing its implications.

\section{Methodology and Materials}

To answer the research questions, we deploy two methods: a narrative literature review and qualitative analysis through interviews and field work. The first method is a narrative literature review [25], which means we did not perform a full, systematic literature review, because we needed only an overview of theoretical perspectives on territorial approaches to a circular economy (the "A territorial Approach to Circularity Discourse and Planning" section) and a historical overview of spatiality in circularity discourse in Japan (the "Results"). The limitation of a narrative literature review is that we possibly overlook important papers or parts of concepts in favour of a focused analysis. The keywords of this narrative search were combinations of a circular economy (or circularity) and concepts such as territorial, cities, areas, and spatial planning. Notably, some evidence originated in debates and conversations we had with landscape designers, urban planners, and rural revitalisation experts in Japan and Europe during the past four years that we have been conducting research on circularity. We also acknowledge additional research that has been suggested by reviewers.

A narrative literature review is often followed by a qualitative analysis [25], and this manuscript is structured accordingly. We draw on field work from Japan and northwestern Europe. One of us specifically researched circularity and rural revitalisation in Honshu, the main island of Japan. The case study is Onomichi, a place this researcher visited several times in 2018 and 2019. She interviewed more than a dozen activists and architects involved in tactical urbanism, followed them on social media, attended several community meetings, and observed social practices. She walked in different places as much as possible, had conversations with locals and was a passive observer to be receptive to new insights about lived experiences of circularity. Walking as a method, often in combination with stakeholder analysis, is not often reported in academic publications, but has recently become more acknowledged by urban geographers to be an inductive method that might 
be less subjective and, especially if combined with other methods, that might add rigor to findings collected by other methods [26].

Notably, the title of this manuscript includes a reference to 'Tokyo Story', a famous movie by Ozu [27] about the lived experiences of an elder couple from Onomichi visiting their overworked children in Tokyo. The movie is a reflection on how traditional values and social structures in postwar Japan have changed because of urbanisation. The case study that we highlight is a kind of 'reverse story' because it is about an opposite movement, i.e. decentralisation, and does not only concentrate on megacities. The normative stance of this paper is to advocate the design of a circular economy that is place-specific, socially robust, and just, both for human and nonhuman stakeholders. If circular economy policies encourage only market solutions and the commodification of spaces and social needs, such as food, they can affect whole urban systems that, for example, support and sustain vulnerable populations (homeless individuals, people without property, unemployed people, etc.) [28]. A territorial approach fits this stance because it examines dimensions other than materiality, such as the even distribution of resources, products, and services, as well as the associated risks and costs. It evaluates circularity instrumentally to achieve higher wellbeing, rather than expressing a goal (of being efficient and increasing profit) that does not prioritise other (social) dimensions including safety or justice.

\section{A Territorial Approach to Circularity Discourse and Planning}

\section{Critique of Circularity as the Panacea for Sustainable Economic Growth}

Today, a circular economy remains a contested and ambiguous concept [29, 30]. Recent studies have highlighted how interpretations of a circular economy are often embedded in particular worldviews and political positions, which usually lead to the diverging paths that circular transitions take in practice [14]. Moreover, in both academic and policy debates, a variety of circular imaginaries have been put forwards, ranging from segmented circular economy perspectives, which focus only on largely economic and technical components of circular systems, to more holistic visions of a circular society that comprehensively integrate the social, ecological, and political considerations of circularity [31]. At the same time, the question of whether sustainable circular transitions are possible within the framework of a capitalist economy has generated further discussions on the need to completely transform a socio-political system to enable ecologic-economic decoupling and a achieve fully circular society [31]. In fact, many contemporary scholars argue that a circular economy and economic growth are incompatible [10, 20, 32]. However, while some of them claim that the various extant circular business strategies and models are neither economically profitable nor practically feasible, calling for 'post-growth' circularity [20], others point out some important fallacies in considerations of a circular economy and its relation to sustainable development. For instance, Skene [32] elaborates on the attempts of circular economy scholars to model circular systems by mimicking the functioning of natural ecosystems and their biological principles, but only to show that 'the biosphere works very differently from any notion of a circular economy' (p. 486). Thus, circular principles, such as tight loops, zero waste, extended lifetimes, and closed systems, would be unable to deliver economic growth and could also be detrimental to many global natural systems. In other words, a CE could undermine all efforts to achieve sustainable development. Moreover, the weak integration of sustainable development principles in contemporary circular economy 
discourses has been widely criticised. The principal concern is that a circular economy cannot support economic growth and prevent the degradation of natural ecosystems while simultaneously promoting social equity and a just distribution of the social benefits that it generates [33]. This critique even suggests that a circular economy may not offer a more sustainable model than a linear economy [32, 33]. For that reason, some scholars have proposed alternative approaches to circular development that better integrate the aim of achieving economic progress and the necessity to address environmental concerns. For example, the notion of 'circular ecology' has been promoted as an alternative and more integrated interpretation of circularity. Drawing on evidence from different circular waste management practices worldwide, Adami and Schiavon [34] present circular ecology as a potential solution for various environmental problems while highlighting its economic benefits [33]. However, these alternative definitions have also been contested, and some authors advocate a deliberately vague and ambiguous discourse and consider circularity a boundary object that could enable a circular economy to gain widespread support relatively quickly [31, 35].

This is particularly evident in local translations of a CE's bundled ideas and principles, i.e. in their common lack of a territorial approach. Policy-makers usually look to (best practices in) other countries to draw inspiration. Both the Ellen MacArthur Foundation (EMF) and the industrial ecology school are major influencers in the development of circularity discourse [2] and the primary sources of inspiration for many cities and countries [36]. The legacy of industrial ecology stems from its focus on the optimisation of material stocks and flows [14]. Industrial ecology is gaining traction with respect to a circular economy because it provides evidence that legitimises the development of the concept of a circular economy and of its technocratic path in particular [30].

Some scholars argue that CE transitions will evolve through territorially differentiated strategies and pathways [37] because of different policies, regulatory frameworks, and geographical features. However, globally, capitalism's use of efficiency as a herald of market economies might lead to greater convergence and preferences for a capitalist circular economy. We can observe this in the cases of the European Union (EU) and China, where the adoption of circular practices has been particularly prominent.

In regard to the EU, a CE represents a 'nexus policy' that legitimises similar ambitions of economic growth but with a kind of sustainability that does not challenge the cultures, identities, and practices that might need to be renewed [30]. The most notable circular initiatives, apart from communication and continuous indicator developments, indicate that the EU is taking a mostly technocratic path [30]. Even the choice of indicators illustrates a tendency to invest in efficiency improvement [30]. In addition, the EU appears to have only 'nudged' CE practices by financing demonstration and pilot projects without strong integrations of spatial and political dimensions [22].

Another territory that has spearheaded circularity is China. China's mode is inspired by the modes in Germany, e.g. its 1996 'Closed Substance Cycle and Waste Management Act' [38], and in Japan, e.g. its ecotown planning in 1997 [39] and recycling-oriented society legislative system, based upon its 2001 Basic Law for the Promotion of the Creation of a Recycling-Oriented Society [40]. Compared to the EU, the Chinese government takes a more planned and coordinated approach with its top-down Five Year Plans and economic concepts, including circularity [22, 41]. According to [41], there were three phases of CE adoption in China; concept advocacy (late twentieth century-2002), action (2002-2009) and full promotion (2009-present).

The Chinese CE is a legacy of China's eco-industrial parks and promotion of industrial symbiosis [42], which evolved with the Japanese ecotown programme beginning in 
1997 [39]. It is based on the idea of maximising the benefits of a proximity to industrial and urban areas but does not necessarily advocate a holistic integration of social impacts. Wang et al. [41] have evaluated 40 pioneering CE cities in China during 2012-2016 by using indicators and targets, which were focused mostly on recycling and imposed by the national government, echoing the value of economic growth. Guo et al. [43] evaluated four cities but mostly addressed their limited waste management efforts. The choice of indicators in both national policy and the research demonstrates a focus on efficiency [44], and the overall approach appears to remain largely technocratic.

Turning to academia, publications on the circular economy have been exponentially increasing since 2015 [45]. However, most research on the issue has taken a deterritorialised approach without translating what circularity means in local contexts. Although several works have explored the roles of space and context in circularity transitions (cf. [1, 4]) or evaluated developments mostly related to waste management (cf. [41]), spatial circular economy discourse is still relatively underdeveloped.

Recently, various publications have assessed implementation designs at local levels [46] or have described tools for CE design [47], approaches that local governments have taken [48] and monitoring systems [41, 49, 50], though these have mostly focused on European or Chinese cases. An interesting group of publications has recently discussed territorial approaches to circularity, mostly among French and Italian communities [3, 14, 51, 52]. This reflects how older theories of territorialism, regionalism, and spatial planning (especially in Western science) have not been sufficiently connected to circularity. This is partly because circularity has emerged from the recent period of deterritorialisation and despatialisation, as observed by several elite researchers, such as Magnaghi [19]. The following subsections provide a short overview of established theories, some of which are hundreds of years old, to better ground the emerging literature on territorial approaches to circularity.

\section{What Is a Territorial Approach?}

To understand what a territorial approach means, it is important to grasp the current meanings of territorialism, regionalism, and Geddessian thinking.

In the early twentieth century, the botanist, urban planner, and social scientist Patrick Geddes introduced interesting concepts, such as the valley plan, which called for considering valleys as specific units for design, planning, and research [16-18]. In his view, a river represents the core of a study exploring relationships between lands, settlement types, human lived experiences, and materials. Geddes [53, 54]

was in turn inspired by ideas of harmony with nature, which were prevalent in Europe as early as three hundred years ago. Humboldt developed the concept of Zusammenhang, central to any idea of harmony with nature [55], which greatly influenced the great town planner Geddes. These ideas clearly call for integrating circularity with agendas that value cooperation, sharing, sharing, community, and solidarity, and that value nonhuman life and its well-being [56, 57].

One important aspect of territorialism is that it challenges the divide between the rural and the urban. Often, urban circularity researchers focus on city boundaries for analysis. However, from a territorial approach, this seems senseless. Circular cities (and cities in general) are made of resources from rural areas and are dependent on mountains, rivers and fields, and the living beings who are there. Friedmann [58] puts forwards the concept of modular cities as ways to bridge urban-rural divides, implying that spatial divisions of 
labour between urban and rural areas are not sharp, but more intricate, with fluid borders and considerable overlaps.

A final important name we want to briefly discuss is Magnaghi [19, 59, 60]. In his draft of the Territorialists' Society Manifesto [60], he advocates a culture-sensitive and placebased approach to circularity and criticises hegemonic political economies that are not able to organically integrate territorial challenges, globalization trends, and decentralisation policies, all of which contribute to 'the elimination, marginalisation, degradation and decontextualization of places, landscapes, people's living environments, and close convivial relations'. This risk of a deterriorialised approach in a circular economy is the basis of our own concern for the social impacts and uneven distributions of local environmental and economic impacts.

Please refer to the recent reviews $[51,52,60]$ for a very robust overview of the French and Italian traditions and schools and of how circularity is integrated in them. Some of the more recent research by Marin [6, 14, 50] and Barles [72], scholars whose work influenced us in our studies on circular cities and territories, is rooted in ideas of territorial ecology and the French school of territory studies.

\section{The Recent Territorial Approach to Circularity}

The territorial approach to circularity is most often demonstrated through the concept of a 'circular city'. Similar to definitions of a circular economy [5], the definitions of circular cities vary. Among the most notable is the one provided by Paiho and her colleagues: '[a] city [that] is based on closing, slowing, and narrowing the resource loops as far as possible after the potential for conservation, efficiency improvements, resource sharing, servitisation, and virtualisation has been exhausted, with remaining needs for fresh material and energy being covered as far as possible based on local production using renewable natural resources' [61].

In addition, a circular city is a social, economic, and political construction. Social impacts are often overlooked in urban or regional ecosystems [62]. A more just perspective would also focus more on the social groups that live and work within the boundaries of a city [63] than on urban innovations. This implies, as advocated by territorialist thinkers, such as Magnaghi, a place-based study of processes, specifically, of the power relations and socioenvironmental conditions that determine which social groups gain or lose from the adoption of a circular city [64]. It is important to identify the winners and losers in the discourse and design of a circular economy. Market-oriented economies, even if they serve 'circularity', do not value and benefit everyone [30,65]. One way circularity can manifest itself is by promotions of 'newness', such as new (circular) constructions and new innovations that capitalists may actually perceive to be delays in diminishing returns [22]. Moreover, circular new constructions can replace functions, such as urban manufacturing, to enable circular activities $[15,66]$. The integration of green areas and reclamation of abandoned spaces also have environmental justice aspects. Environmental gentrification can lead to an increase in land and housing prices and to the displacement of people with low incomes [67-69]. As some so-called circular jobs (waste pickers, repairers, farmers, etc.) are not highly valued, e.g. in the income they receive, they cannot pay increased land and home prices and must relocate to less healthy places (slums) or locations further from their workplaces. However, their roles and conditions can be overlooked by certain framings. Aiming to make planners and policy-makers aware of different theories and values, Marin $\&$ De Meulder differentiate between four theoretical agendas in an urban circular economy 
that are based on urban landscape theories and conclude, 'with an agenda for multiperspective and multidimensional circular city design, which is anchored in place specific and multiscalar transition relations' [14]. One of the four agendas includes a democratisation aspect that implies an extension of the narrow concept of circularity beyond its extant focus on waste and businesses to encompass the human and logistical resources needed to enable circularity. For example, a company can create zero waste products but cannot be disconnected from or is dependent on a carbon-intensive infrastructure, while the people who need its products or the hinterland that might supply its inputs and/or this company could be too far from the labour pool. The authors advocate integrating all four agendas, which also means integrating the ideas of bottom-up and nonmarket practices. Moreover, other researchers advocate a social dimension and the integration of existing ideas, practices, and different types of knowledge in the development of what they call a circular society [31]. These ideas are all familiar to territorial scientists, who consider territory a common good and criticize the currently dominant political economy of economic growth and the ecomodernist focus on technological fixes, deeming them incapable of integrating territorial problems [60].

\section{Results}

\section{Some Historical Context on Japan's Environmental Management Since Industrialisation}

In Japan, a territorial approach to the circularity or metabolism of materials has existed for many centuries. The ideas behind the concept were all present in Japan before circularity, as a concept, became popular and adopted globally. While the main focus of this research is on contemporary developments, this section provides a brief historical overview of concepts, ideas, and practices of circularity in Japan.

\section{Japanese Edo-Period (1603-1847)}

In his Gaia Atlas for sustainable cities, Girardet [70] divided cities into biocidic and biogenic cities. Biocidic cities have a linear economy; they take resources from nature but do not invest in their regeneration, resulting in the collapse of these cities [70]. In contrast, biogenic cities are in balance with the rest of their environments, taking care to maintain their lands and returning human and animal waste to their ecosystems [70]. The towns, villages, and cities in the Japanese Edo period (1603-1847), when Japan's borders were closed to the rest of the world, could be considered biogenic cities. A circular metabolism was spatially present, linking 'night soil' to agricultural systems and repurposing bath water [71]. Waste did not exist in Edo-Japan [71], which was also the case in European countries and cities in earlier times [6]. Outflows were appreciated as bioresources at these times. As the material cycles were also very localised, everyday resource management was easy. Amidst early industrial revolutions, byproducts were valued. It was only with the introduction of artificial fertilizer, petroleum, and other technical innovations that some biobased byproducts, such as 'night soil', became waste or obsolete and thus a burden to society [72]. In Japan, people often refer to satoyama (landscapes embedded with forests and mountainous villages) (Fig. 1) and satoumi (landscapes located near a sea). These are traditional cultural production landscapes that are created through human and nonhuman 

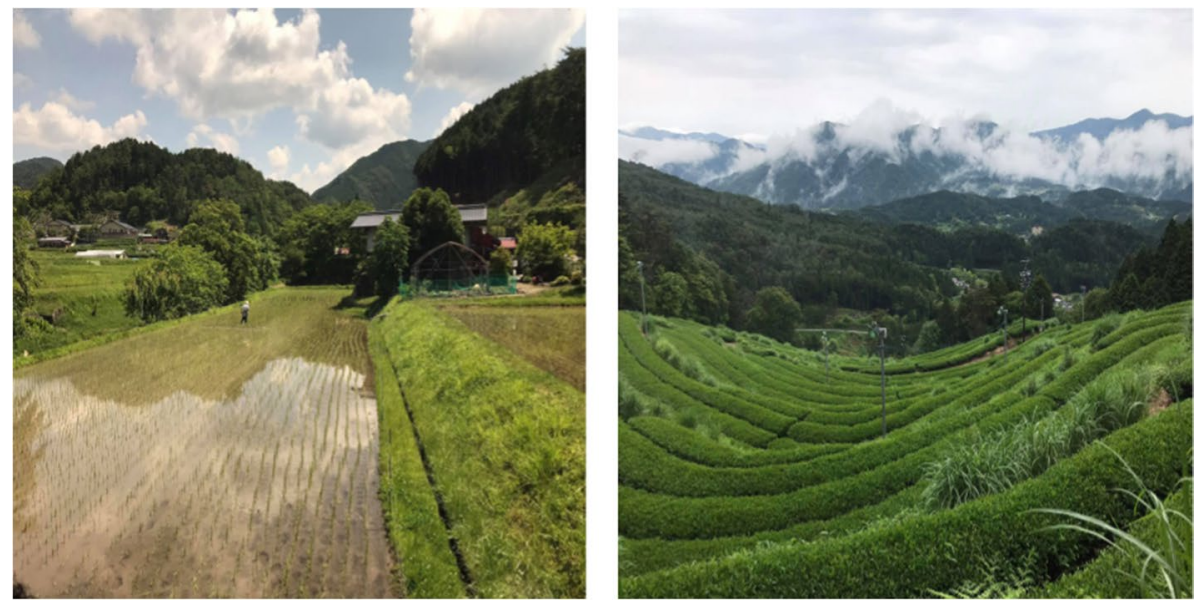

Fig. 1 Photo collage of visits to actors in various agricultural, forestry and processing sectors in satoyama landscapes, Gifu Prefecture, which were part of a transdisciplinary research project about rural revitalisation. Source: by first author, May-June 2018

interactions, fostering biodiversity and local cyclical uses of bioresources [73]. The satoyama landscapes maintain ecosystem services that benefit local natural human and nonhuman well-being [74].

\section{Rapid Industrialisation, Technological Evolution, and Introduction of Public Hygiene and Safety Approaches (1847-1945)}

After the Industrial Revolution reached Japan, more infectious diseases started to plague the country (as in other parts of the world). The sources were unsanitary water channels and disease-bearing animals, which led to the initiation of laws, such as the Dirt Removal Law in 1900, and improvement measures for night soil management [75]. Public hygiene became an important topic in management and policy responses [75]. In the Meiji Era (1847-1912), Japan changed from an isolated feudal society to a modern industrialised nation state characterized by rapid industrialisation and technological advancements [75].

During this time, the effects of earthquakes and other natural disasters became more profound, as citizens started to concentrate in cities. For example, Yokohama City is the second-largest city by population and the most populous municipality in Japan. It lies in Tokyo Bay and has experienced rapid development since the mid-nineteenth century (following the end of Japan's relative isolation) because of its port infrastructure. Yokohama experienced the 1923 earthquake, which originated in the Kanto region and destroyed most of Yokohama's buildings. The memory of this still informs how the city copes with disasters and emergencies and an awareness that we find in social businesses (e.g. Solarcrew business [76]) regarding strategic developments in the area (FutureCities policy [77]). For instance, Solarcrew aims to reclaim vacant houses as spaces for connection in times of peace and as shelters in times of emergency [76]. In summary, rapid industrialisation and urbanisation - in combination with a geography with a high frequency of natural disasters and compact living - generated the need to adopt a security and public hygiene approach in Japan's urban management, which still frames national policies, standards, and concepts. 


\section{Public Health in Postwar Environmental Policies (1945-1999)}

In the immediate aftermath of World War II, the links between different health impacts and industrial activities became clearer. For example, the itai-itai disease was the consequence of cadmium pollution of waters through mining activities in Toyama prefecture [78], and there was air and water pollution in heavily industrial areas and cities, such as Kitakyushu in Fukuoka Prefecture [79]. Additionally, in the late 1950s and early 1960s, the satoyama landscapes started to decay as a result of imports of external foods, energy sources, and fertilizers that broke their cyclical use of local bioresources and of depopulation [80, 81].

Various waste and public cleaning acts were established in the second half of the twentieth century, such as the Public Cleansing Act of 1954 and the Waste Management and Public Cleansing Act of 1970 [80], as policy responses to the environmental pollution problems resulting from rapid reindustrialisation in the postwar period. There was also a growing awareness of waste production, which resulted in laws and policies to stimulate sorting and recycling, starting with the First Recycling Act in 1999 [75]. Recycling and incineration are currently very efficient in Japan. The problem, perhaps, is that Japan became a victim of its own past successes (lock-in effect) (Fig. 2). When recycling regimes become 'too' efficient, they reduce the incentives phase out extant waste recycling and incineration regimes for more desirable circular strategies (preventing waste production) [82].

\section{The Fukushima Nuclear Disaster: Revamping Traditional Socioecological Landscapes, Connecting Rural and Urban Components and Calls for Decentralisation (2000-present)}

In the early 1990s, the destruction and mismanagement of forests and satochi-satoyama (socioecological production) landscapes was acknowledged together with the need for bioconservation. Early research efforts on watershed management comprised the pioneering activities that led to the creation of the concept of Society in Harmony with Nature [81].

Fig. 2 Visit to a waste management plant facility in the Yokohama region. Source: First author, March 2018

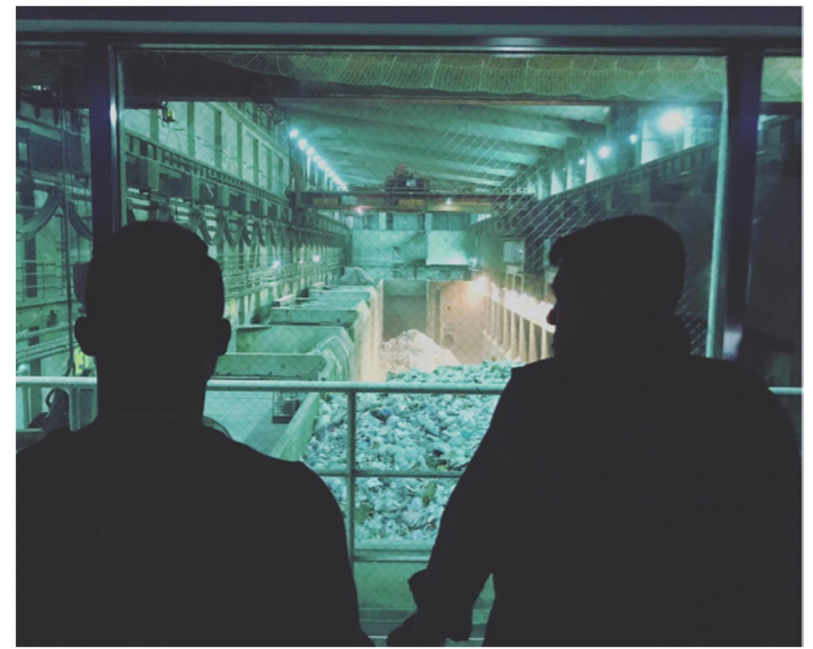


In 2010, the Satoyama Initiative was established to promote the importance of traditional knowledge regarding these landscape systems [83].

In 2008, the Japanese government put forwards the idea of the Regional Circular Sphere, but similar concepts had already appeared in the actions of local governments, civic organisations and academic researchers [81]. Together with the concept of the Society in Harmony with Nature, the Regional Circular Sphere would become the basis for the Circulating and Ecological Economy (CEE), launched ten years later [81] (and elaborated on in the next section). After the Great East Japanese earthquake in 2011, which revealed weaknesses in centralisation, actors began to see these ideas in light of local societies' opportunities for revitalisation [81].

\section{Circularity Concepts in Japan}

Even before the launch of the Basic Laws that inspired, for example, the Chinese mode of circularity, Japan had launched the Eco-Town Programme in 1997, focusing on industrial symbiosis and urban symbiosis to optimise the economic and environmental benefits from the proximities of industrial and urban areas, with an emphasis on waste disposal [39, 84].

Four years later,the Japanese government launched the Basic Act for Establishing a Sound Material-Cycle Society [23], which can be considered a call to transition towards a circular economy. Article 2 states the following: 'a society in which the consumption of natural resources will be conserved and the environmental load will be reduced to the greatest extent possible, by preventing or reducing the generation of wastes, etc. from products, etc., by promoting the proper cyclical use of products, etc. when these products, etc. have become circulative resources, and by ensuring the proper disposal of circulative resources that are not put into cyclical use (i.e. disposal as wastes)' [23]. It provides quantitative targets for recycling and dematerialization in Japanese society [39].

In 2003, the Fundamental Plan for a Sound Material-Cycle Society (FPSMCS) was adopted by the Japanese government, and a set of three economy-wide material flow indicators and numerical targets were introduced [85]. In 2004, the Basic Law for Establishing a Recycling-Based Society was adopted through national legislation [40].

Meanwhile, bottom-up initiatives started to expand, including the famous Zero Waste Initiatives and their known example of Kamikatsu, which had 20 years of experience [86]. All these practices and policy responses reflect a waste approach and a call to optimise recycling regimes.

In 2018, the Fifth Basic Environment Plan of the Government of Japan was published, institutionalising the Circulating and Ecological Economy (CEE) and Circulating and Ecological Sphere (CES) 'to localize the flow of resources between urban and rural areas' [81]. Notably, CEE and CES were based on existing traditions and were built on Japanese concepts and ideas, such as satoyama and satoumi [73, 81]. Some cities have been adopting (or have at least planned to adopt) circularity in their policies (e.g. Kitakyushu, Toyama, Shimokawa, etc.) [87]. This is a particular kind of circularity that places great emphasis on the integration of urban ecosystems with their rural hinterlands (to promote regional revitalisation), on the shift to a renewable energy and natural resource-based economy (agriculture and forestry), and on the primacy of local/regional landscapes [81, 88, 89]. These concepts have also been exported to other cities and regions in Asia, such as Nagpur in India [90], and other practices outside Japan have been labelled CEE [81]. In addition, CEE aims to foster the goals of a sound material-cycle society [83]. In the Yokohama region, for 
example, local seaweed farms in coastal areas found different resource uses (such as fertilizers and foods) by cooperating with citizens and teachers [91].

Since 2019, the national government has promoted the concepts of SDG FutureCities and Eco-Model Cities. The former specifically addresses future challenges, such as ageing populations and environmental challenges; the latter has spearheaded the first comprehensive efforts to create a more sustainable, low-carbon society [77]. Cities that have embraced these concepts have also integrated circularity principles and practices, as shown in Yokohama. The Ministry of Economy, Trade and Industry (METI) and Yokohama City strongly engage in a circular economy through their policy practices. Yokohama City has launched several smart-city projects (e.g. introducing home energy management systems encouraging the sharing economy, such as sharing-mobility services called baybike and electric vehicles) [77]. As an EcoTown and FutureCity, the city identified four model districts. This pathway focuses on 'optimising', i.e. on building 'new' systems, technologies, or cities by utilizing new materials or unoccupied lands.

In 2020, the Japanese Ministry of Economy, Trade and Industry (METI) launched its Circular Economy Vision 2020, calling for new business models, better evaluations of markets and establishing a resilient resource circulation system [92]. One year later, METI, together with the Ministry of Environment, released guidance for companies [87] with a focus on market solutions, monitoring through indicators, and plastic uses (pollution in marine areas).

\section{Circular Onomichi: a Demonstration of Practices, Lived Experiences and Tensions}

In Japan, demolition is often used to clear vacant structures, which are often seen as a problem rather than an opportunity [93]. Less attention is given to utilizing existing materials, resulting in a fragile existing-stock market in Japan (i.e. generational transactions dominate the existing housing market) [94]. To the authors' current knowledge, there are no largescale 'circular (utilizing existing resources to make a sustainable economy)' developments or related policies in Japan. This subsection focuses on opportunities in wastescapes articulate the practices and tensions that can arise in a circular built environment. Wastescapes are landscapes that result from a linear economy and its spatial consequences, often visible as abandoned areas and ineffectively used areas [95].

In many cities, different agendas, including job creation, housing demand, housing quality, housing affordability and climate change adaptation, produce land-use tensions and barriers [96]. As many cities, including growing cities with rising land-use tensions, cope with permanent/structural abandoned buildings and sites, such wastescapes could become the cradles of circularity approaches to urban planning. Wastescapes could play both a demonstrative role of certain practices in circular construction and an enabling role of related non-construction practices, as already demonstrated in Europe [95].

\section{Context of a Specific Case of Wastescapes in Japan}

Postwar 20th-century Japan was characterised by the upward social mobility and geographical relocation of a majority of citizens, who shifted from rural areas to cities [97, 98]. This movement triggered issues such as erosions of local economies, losses of culture, and 
dispersals of residents across large areas, which induced loneliness and created difficulties for providing good-quality public services [97, 98]. Currently, local government administrations compete to attract more (taxable) residents to revitalise their regions.

Empty and short-lived houses are thus symptoms of a combination of demographic changes that began in the 1950s, including neoliberal housing policies, changes in people's lifestyle preferences, and women's economic advancement [99]. These novel lifestyles were car-oriented, gender-biased, family-oriented, and supported by a strong ideology of home ownership [94]. However, due to the Vacant House Special Measures Act of 2015, which gave local governments more power, different strategies have emerged, including renovation subsidies or free housing, but these strategies will not revitalise wastescapes (Interviews Onomichi 2018). Onomichi is a model town of the practices that transform wastescapes in vital neighbourhoods, and an example of tactical urbanism that has been visited by many grassroots organisations to study its governance regarding its use of vacant houses and space.

\section{Introduction to ‘Circular' Onomichi}

Onomichi is a town situated on an inland sea in the Hiroshima Prefecture with a population of 150,000. Recently, Onomichi has been recognised as a 'model town' due to its preservation of kominka, traditional Japanese houses with a wooden structure. Spared from bombing during World War II, Onomichi contains a high number of old buildings, which have been retrofitted as cafes, shops, galleries, and more by various communities. However, ten years ago, it was a wastescape with a high percentage of vacant houses, an elderly population and a monoculture. In the past ten years, newcomers moved to Onomichi to rebuild not only houses but also their lives (interview May 2019, Onomichi). Onomichi is a place of becoming with many meanings. The values of members of these communities of old inhabitants and newcomers include the preservation and revival of both available resources and existing structures. New actors are challenging the right to revitalise the small city. Not only larger companies have invested in urban real estate, but also nonhuman animals, such as cats, are occupying these wastescapes and transforming them according to their needs. Their activities will be framed by the discourse of circular cities because the practices of humans and nonhumans can be linked with principles of circularity and even with more desirable CE strategies (as stated by Marin \& De Meulder [100]). Although Onomichi does not have an officially circular economy, this case study presents a pathway to a circular city, contributing to the limited literature that investigates wastescapes as opportunities for developing circular and vital towns.

\section{The Most Circular Actions Are 'Passive' from a Capitalist Perspective}

As demonstrated in the hierarchy proposed by Marin \& De Meulder [100] and supported by critical examinations of circularity imaginaries [101], doing nothing can sometimes be the best 'action'. Often, we feel we must immediately act, construct, or create because of an action bias, especially in capitalist societies [30]. This subsection describes what this means practically and criticises the tensions that it produces.

Onomichi has an attractive setting for studying the 'passiveness' that a genuine 'circular society' [31] requires: its hills are seen as 'sacred spaces' and the lands on the mountains 
are owned by several temples because they are full of cemeteries. It has always been forbidden to build houses there, except at the end of the nineteenth century. At that time, railway construction displaced many households (Interviews February, August 2018). Consequently, protests of the homeowners led to the approval of their houses being constructed in the holy mountains (Interview, August 2018). Therefore, land in Onomichi is mainly owned by temples and many middle-class families. Newer legislation forbids new construction on places that exceed an inclination threshold, and a considerable part of the historical district is built on steep hills (Interviews February, August 2018). The houses that are still there were built in earlier times when such legislation did not exist. The danger to them became apparent during heavy rainfall in the summer of 2018: a landslide destroyed some housing in this hilly area. Currently, many spaces located on the hillsides are overgrown by nonhuman nature. Some houses and gardens have been rewilded and thus their houses cannot be restored to their original forms (Fig. 3).

Sometimes, citizen communities organize clean ups of spaces to create safe playgrounds for children that are far from motorized traffic (Interview Onomichi August 2018). The infrastructure in these hills was designed when motorized vehicles were not common. Due to legislative frameworks, its form is fixed; it still cannot allow motorized travel (Fig. 4). This strategy of letting nature 'overgrow' is not the product of political will or activism but a consequence of changing legislation and norms. Newcomers who live here purposely choose a life of 'less convenience and more slowness'. These designs create spaces of socalled conviviality [22]. However, these aspects have disadvantages for elderly individuals that are rooted there and increase labour costs for activities such as repair and maintenance.

Additionally, there are tensions between humans and nonhuman nature. Some people are afraid of the more-than-human world (snakes and bugs) and are greatly concerned with hygiene. Japanese people consider abandoned houses as 'diseases' [102] because they perceive them to be places where hazardous pests can develop. In municipality plans in Japan about the management of vacant housing, the indicators that determine the ranks of vacant housing are not based on potential but on risk, such as safety (collapse) and hygiene (and, to a lesser extent, health) [47]. Some people dislike the
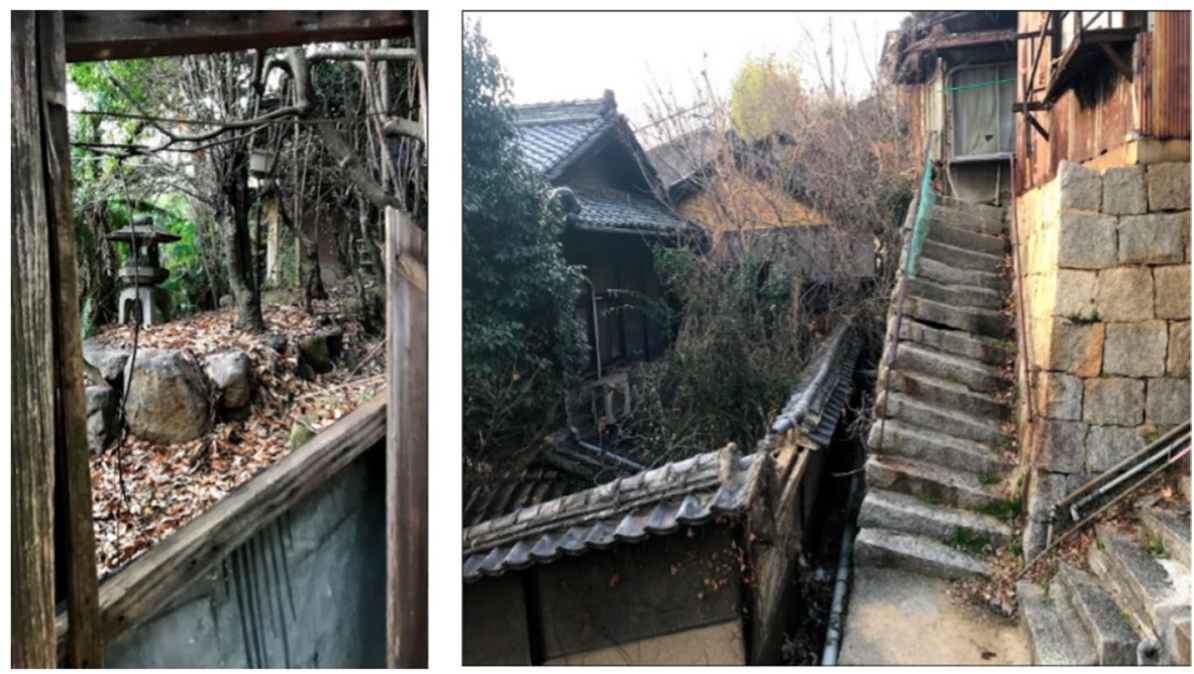

Fig. 3 Collage of rewilding. Source: First author, January and February 2018 
Fig. 4 Material travels via nonmotorized transport. Source: First author, May 2019

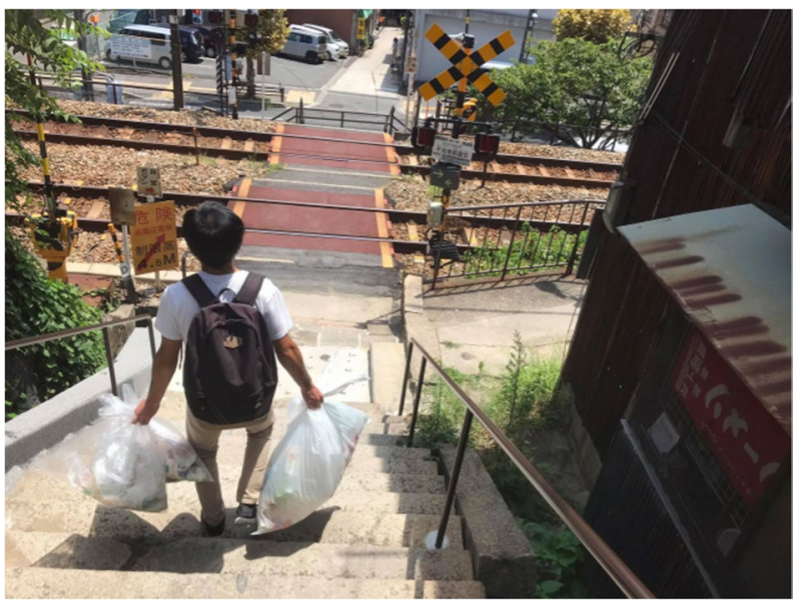

untidiness that street trees and animals can leave on their cars and other properties (convenience/comfort issues). There is also the problem of free-drivers in common areas (littering). However, in Japan, local communities engage in nonlegal social control mechanisms to protect their areas [103], including conservation efforts in national nature parks [104]. Litter or other symptoms of disrespect are seldom observed in Japan, including Onomichi, except within some vacant spaces-which are not considered public spaces. In Onomichi, some of them contain dumped waste and materials (observational notes Onomichi January, February 2018, Fig. 5).

In urban places in Europe, one observes conflicts between utilities (such as underground electricity networks) and root systems of trees. In Japan, however, many utilities are aboveground because of earthquakes and other disasters. There are also some nonhuman beings that can harm humans (e.g. mosquitoes and ticks that carry diseases). Significantly, as climate change increases, diseases will spread more easily in warmer urban heat islands [105]. Different residents of this greener area in Onomichi often
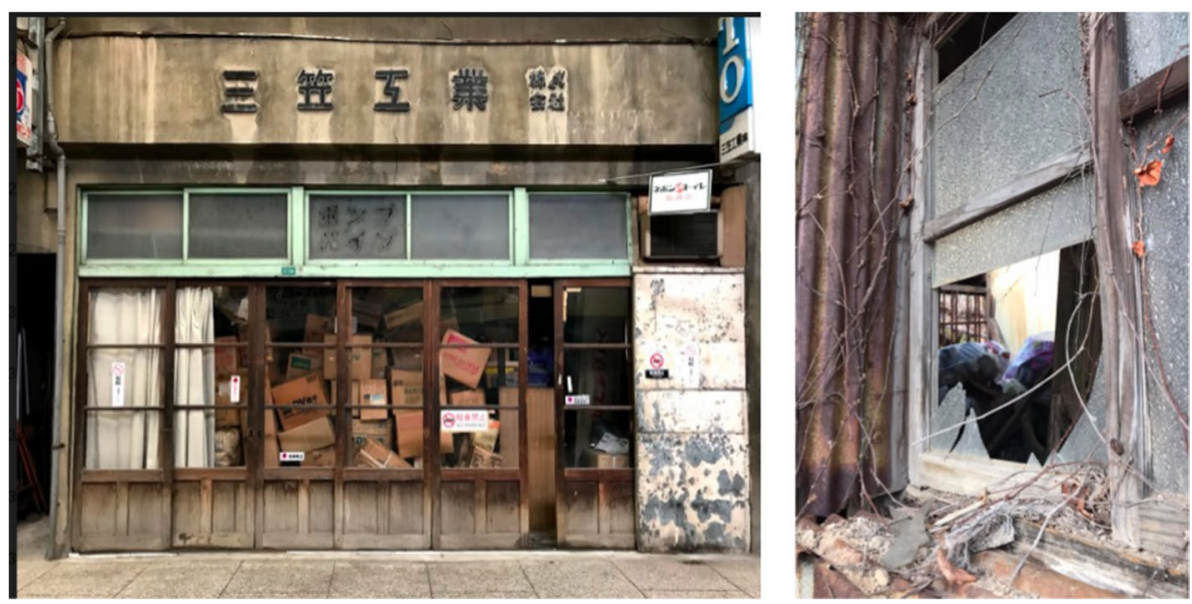

Fig. 5 Peeking in empty houses, seeing a different Japan. Source: First author, February 2018 
complain about the number of bugs and the unbearable heat in the summertime. Nevertheless, these were not the reasons that people moved out of its vacant places.

Finally, regarding 'regeneration', abandoned places do not exist from a posthumanist perspective [106]. There are other living beings that occupy these spaces, and thus certain ideas, such as Louis Le Roy's ecocathedrals or Escobar's pluriverse designs, might help initiate 'green participation' [107]. Unfortunately, in 'market economies', plants and animals are often overlooked; therefore, as CE discourse and policies only account for market economies, the most desired CE practices, in terms of multispecies justice, might be overlooked [22].

\section{Working with Existing Structures}

By adopting a circularity policy that focuses on existing structures, Japan would obtain the means to reduce its international independence and reduce its global impact. 'In circular urbanism, as much is adapted as possible and as little is built as possible. At least, it is dismantled, rearranged and adapted, repaired and, at best, overgrown' [100]. This idea of avoiding a tabula rasa approach is also present in territorial and Geddessian thinking [16, 53, 54].

Reclaiming and repurposing vacant houses can be driven by different reasons. Our case studies in Onomichi are mostly related to historical preservation. In the interviews in Onomichi, it was stated that environmental awareness was not the primary motivation behind such reclamation activism. There are tensions between historical preservation and different sustainability goals [108].

Interviews with frequent visitors and residents indicated that the landscape has visibly transformed over the past decade. Ten years ago, an ageing population and abandoned houses characterised the historic district. Now, however, the area thrives, with young families occupying and renovating these houses and turning them into their homes or repurposing them as shops, art galleries, coffeehouses, and guesthouses. In Onomichi, the governance of these vacant constructions has been managed by a Nonprofit Organisation (NPO) for more than a decade; this NPO negotiated with the local government to control the 'akiya (Vacant house) databank' (Interviews January February, August 2018). One reason Japan has so many vacant houses is legislative frameworks: homeownership is highly protected, and local governments have almost no power to claim vacant houses. Moreover, there are no records of who becomes the next owner after the previous owner dies (Interviews February 2018, Onomichi). Due to the Vacant House Special Measures Act of 2015, which gave local governments more power, local governments launched different strategies, including renovation subsidies or free housing policies (ibid.). However, finding subsequent owners or new buyers is a time-consuming process. Onomichi's local government trusted this NPO to fulfil this role; the fact that an NPO manages this is not common in Japan.

This NPO, the Onomichi Abandoned House Reclamation Project, is strongly embedded in local social networks and communities. One of this NPO's roles is to enhance social capital among people with and without skills, financial means, and tools. As the director of the NPO said, 'I do not have skills, but I am good at connecting people' (Interview, Onomichi, August 2018). Although some activists in Onomichi reclaim houses and renovate them because of their affordability, the NPO's leaders (the director, an architect) are motivated by cultural preservation. They also actively promote cultural heritage protection 
on social media. These individuals are well known throughout the town; other interviewees frequently mentioned the NPO's director. Social capital is considered both a resource and an enabler of goals such as mental health and well-being. Many interviewees stated that they feel motivated to help in the community and have an authentic life that they cannot find in other contexts. Thus, as an interviewee said, 'it is not only about rebuilding houses but also about rebuilding your life'. On the other hand, this close-knit society also has negative aspects, as mentioned by some interviewees.

As a result of their efforts and their partner organisations, Onomichi has earned a reputation for its DIY movement, as it provides many 'teachers, free tools and empty houses' (Interview Onomichi, August 2018) to individuals who do not have sufficient funds to transform an empty house into a home and/or a small business (ibid.). Newcomers reported how funds have been raised to aid their restoration efforts. For example, due to crowdfunding organised by the NPO, one young carpenter learned traditional techniques to restore Onomichi's 'Gaudi House' (Fig. 6).

When houses in this district are determined to be obsolete for residential functions, the NPO Onomichi Abandoned House Reclamation Project helps find the labour and other necessary resources to empty and demolish the structures. Then, they assign new functions to the land, plant trees, organise communal work, and create green spaces and playgrounds (Interview, Onomichi, August 2018). They are not the only players. Recently, financial capital-rich manufacturing industries have started to reclaim abandoned spaces or apparently obsolete places to make them more attractive to and more convenient for visitors with higher incomes. They have deconstructed completely or partially old buildings and reconstructed aesthetically pleasing buildings for visitors (Interview, April 2019). They invite globally renowned interior designers and request that they use local resources to upgrade the spaces. They still promote the history and cultural identity of the city in their marketing, as well as the uses of the materials reclaimed from the vacant houses. For example,
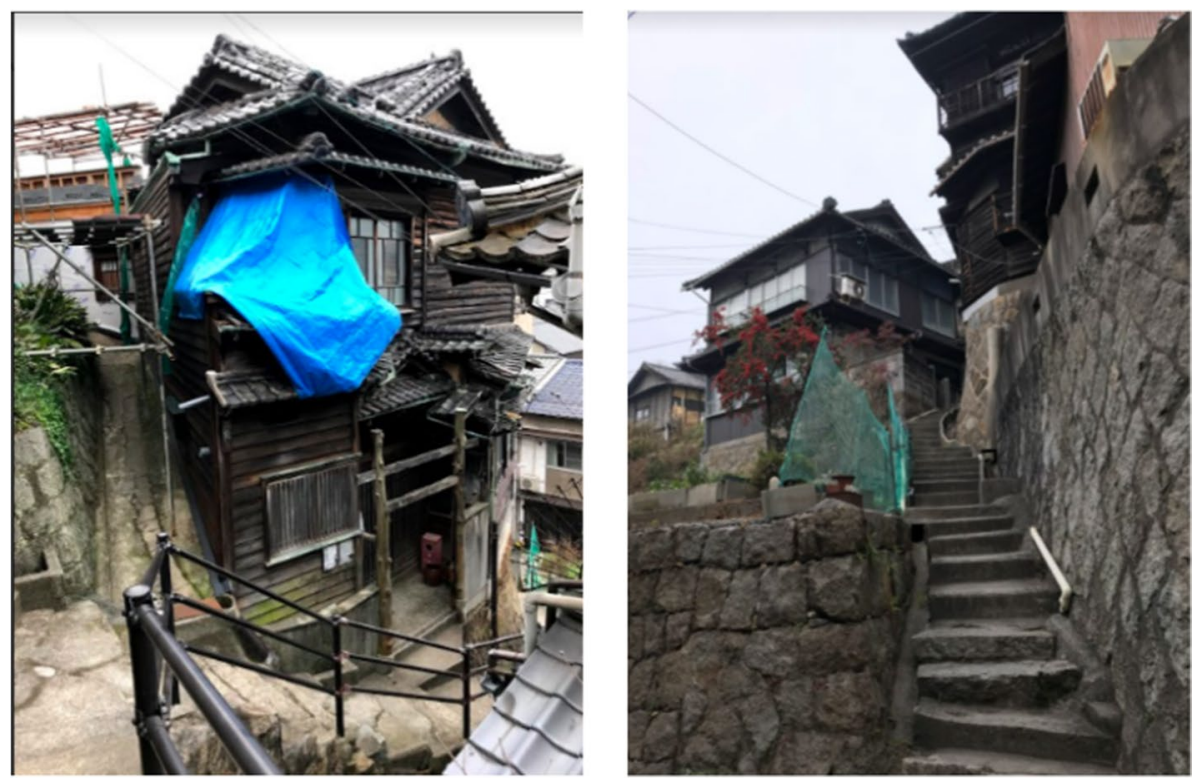

Fig. 6 'The Gaudi House'. Source: First author, February 2018 
tiles of an old house were repurposed in a garden design. Currently, there are no tensions, as their activities attract potential newcomers to the reclaimed abandoned houses-turnedpartially into-businesses (Interviews, April 2019). These companies were also involved in rebuilding the historic train station into a modern complex, which is 'maybe more convenient, but does not represent Onomichi anymore' (Interview, April 2019). On the other hand, many residents born in Onomichi enjoy the new conveniences; dislike was expressed mainly by the people who had moved there. As one immigrant observed: 'There are two camps. The gentrifiers and then the group of the NPO, a restaurant company and other individual rescuers who reclaim because they want these houses and buildings to be there, not to get profit.' (Interview, April 2019). It was also stated that tourists comprise sources of extra income.

The recirculation of materials is not only performed by larger corporate organisations. One of the partners of the NPO is a group of artistic researchers who harvest local materials from abandoned houses that have deteriorated, store them in a community house, and invite local and foreign visitors to repurpose these materials for their arts or other crafts (Fig. 7). There is a mix of different actors engaged in this circular practice.

\section{Discussion}

Circularity is about both maximizing/optimising resource utilization and increasing the capacity of urban ecosystems to regenerate or, to borrow the word from Genovese and Pansera [22], conviviality. Japan is familiar with bottom-up projects, where local players experiment with finding new purposes for materials and abandoned houses, other infrastructure, and places (e.g. Nagano Rebuilding Center, Onomichi Empty House Reclaiming Project). Nevertheless, these projects are tactical and temporary, limiting the scales of these experiments and living circularity labs. These places are available for low-value activities, which is also a precondition found in European cases of tactical urbanism [13]. Although bottom-up practices are examples of responses to current symptoms of the linear economy and initiatives, such as Circular Yokohama's platform, that showcase other ideas aligned with the CEE concept [109], the Japanese discourse is oriented towards 'new' technologies, designs, cities, materials, and lands and less focused on the potentials of existing
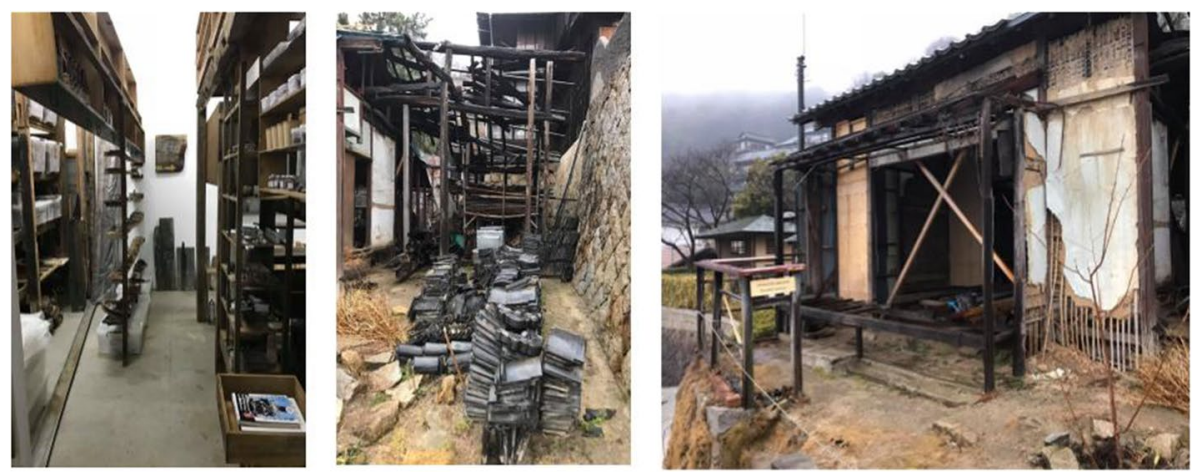

Fig. 7 A small mine (a, b) and a material bank (c) of secondary resources in Onomichi. Source: First author, February 2018 
flows and stocks. The 'planned eco-town' pathway is present in Japanese cities, embodying Japan's 'innovation discourse'.

On the other hand, CEE might provide another way, with different values that promote interactions of humans and nonhuman nature, acknowledge the spatial range of operations, and value traditional knowledge.

The primary difference between Europe and Japan might be that European researchers and practitioners typically focus more on manufacturing industries (e.g. construction, industries in ports) and on circularity in urban economies than on interactions between urban and rural components. The CEE concept acknowledges global urbanization and in Japan but specifically emphasizes how this process and urban economic growth occur at the expense of rural and peri-urban surroundings [88].

However, these differences between the European discourse of CE and Japanese CEE are blurring, as European researchers continually integrate large-scale, urban greening, and other regenerative economy strategies [13], investigate city-hinterland interactions regarding nature-based resources [110] and reconnect research on territoriality and regionalism with CE implementation [51, 52]. In practice, there are also initiatives in Europe to establish rural circularity, such as Zero Waste Scotland's 2020 Circular Highlands and Islands project [111]. Moreover, CEE is a concept instituted by Japan's government. Some activities in Japan are identified or, rather, labelled CEE, as outlined in IGES reports [81], in the cases of Nagano and Shimikawa. Often, these activities were previously labelled (or remain) part of the Satoyama Initiative (cf. [83]). However, little is known (at least in English literature) about CEE's possible tensions, barriers, preconditions, and spatial, technical, economic, and other requirements.

In the European context, the theories of circularity in urban planning have led to different sets of best practices and development plans [3]. The same observation can be made for Japan. The pathways in Japan are primarily about eco-town planning or symbiotic partnerships involving the renewable resources of a city and its hinterland. Nevertheless, there are also bottom-up initiatives that could be labelled circular, from zero waste bottom-up town initiatives to top-down and national concepts, such as the sound material-cycle society of these more recent CEE and CES concepts. Additionally, some stakeholders use the label 'circular', as in bottom-up initiatives such as Circular Yokohama, to assemble smaller, often isolated practices within a city (region).

Few English studies have been published about the contested discourse in Japan. This discourse synthesises the trajectory of circularity in Japan and outlines the tensions among different stakeholders. 'Circularity' practices, concepts, and policy responses could be driven by various stakeholders and underpinned by different concerns including material security, hygiene, public health and safety, biodiversity loss, etc. However, it is not yet clear whether and how they create tensions and barriers during transitions. It is only clear that circularity and sound material-cycle concepts are contested definitions in Japan, leading to different pathways and approaches. The focus of Japanese stakeholders, such as the national government, the Ministry of Environment, Ministry of Economy, Trade, and Industry, and Yokohama City, on optimising and innovating flows and stocks demonstrates that capitalist ecomodernist ideas are also present in the Japanese way of thinking. However, it might be challenged by indigenous concepts, such as satoyama initiatives, CEE, and CES.

Japanese people circulate an economic policy that focuses mainly on building 'new' systems, technologies, or novel utilizations of new materials or lands. This is also visible in other policies: both governments and private companies prefer building new structures after destroying existing buildings or transforming rural lands into urban ones; less 
attention is given to utilising existing materials, resulting in a fragile existing-stock market in Japan (specifically, among generational transactions that dominate the existing housing market) [94]. This is partly because of Japan's incredibly rapid urbanization and population growth that began in the 1950s. Growth-oriented policies and building methodologies dominate Japanese society, as demonstrated in Tokyo [101]. No large-scale projects or policies that focus on the utilisation of existing materials, knowledge, and practices are known. Demolition in Japan is the primary solution for abandoned spaces [93], given the national focus on newness, not revitalisation.

Although the Japanese land ownership tradition and its strong interrelationships of family, housing, and welfare impede the actualisation of an essentially circulating economy, future research can analyse the reasons from social-scientific perspectives (e.g. urban geography, housing studies, or sociology) and evaluate more cases to provide a more accurate picture of circularity discourse development and policy responses in Japanese spatial planning.

Although our focus in the discussion is primarily on the differences between Europe and Japan (as we studied Japan initially through Western glasses), we want to acknowledge the wealth of literature on the Chinese approach, and the link between Chinese and Japanese circularity since China based its approach on the Recycling-Based Society Law in Japan.

In 2021, the 14th Five-Year Plan was instituted, introducing the Dual Circulation Strategy (DCS) Paradigm $[112,113]$. Although DCS is not directly related with circular economy, as a more strategic reorientation towards domestic consumption, it is the notable result of concerns about internal problems stemming from a lack of integrating territorial problems. One of the major motivations behind DCS comprises food and energy security concerns and, of course, concerns about environmental health, especially in the food sector. The focus on the domestic market (considering the macroeconomy a circular system) might influence localisation and better serve local/national communities, but it is too early to observe such effects. Future research can therefore investigate the impacts of DCS on circularity policy and practices in China.

\section{Conclusion}

First, the differences between the circular economy concepts in Japan, China, and northwestern Europe are examined to explain the differences between a territorial and a deterritorialised approach to circularity. We advocate a territorial approach by first elaborating the criticisms and descriptions of the contested concept of circularity and then connect circularity to established concepts like territories, regionalism, and Geddessian thinking, specifically in the relevant Western academic literature.

Through a narrative literature review, we provided a historical perspective of circularity discourse in Japan. In this paper, we argue that the Japanese approach to circular practices can offer an example of a more place-bound and just pathway and act as a counterpart to the European and Chinese ways. To support this, we first trace the roots of spatial circularity in Japan from a historical standpoint before discussing some contemporary circular concepts. We then presented a detailed analysis of lived experiences in the wastescapes in Onomichi, which demonstrate that although more orthodox understandings of circularity permeate Japanese discourse, alternative considerations can be found that promote interactions of humans and nonhuman nature, acknowledge a spatial range of operations, and value traditional knowledge. 
Although it seems that Japanese concepts like CEE and CES indicate a more territorial approach in Japan than those in China or northwestern Europe, other concepts reveal Japan's rather ecomodernist approach. The same contesting discourses and approaches are also present in China and northwestern Europe. Specifically, in the latter, new interests among researcher and practitioners in territoriality, regionalism, and urban planning for circularity seem promising and might revitalise (calibrated to the new contexts) the circularity practices that were observed earlier in the histories of these places. This manuscript contributed to this emerging research on territorialism in circularity by sharing more knowledge about Japan.

The choice of Japan and of Onomichi as a specific case study created many limitations for our research design. One of the biases and limits are our Western glasses. We are both Western researchers with thinking that was initially formed by Western discourse and epistemology.

The first author did not speak Japanese when she arrived in Japan for the first time. The results were limited because we were dependent on English research or voluntary translations by peers. Additionally, few Japanese people speak fluent English, which also limited our sample of participants for key expert interviews. There might be a bias in this sample because we obtained only the views, opinions and knowledge of people who already have the capacity to speak two languages. Another problem stems from the risk of information getting 'lost in translation' [114]; some ideas and concepts are difficult to translate from Japanese to English, not only because of language barriers but also because of disparate epistemologies and cultures. There have been occasions that Japanese people who are fluent in English had trouble translating abstract ideas from Japanese official documents into English for us. Some concepts and ideas, including the ones related to circularity, are embedded in different epistemologies, cultures and even normative stances. For example, even the words for nature and wild in Japanese do not have the same connotations as in English or our mother tongues and their connotations have changed over time, similar to how the relationships with nature changed in our cultures [115]. In future research, we would like to engage with bilingual Japanese researchers who are sensitive to the linguistic cultural and epistemological boundaries to provide a more critical overview of answers to our research questions.

Second, we want to emphasize that the second part of the manuscript, which is focused on a specific place that illustrates what abstract circularity concept can mean in everyday practices and lived experiences, does not represent the whole of Japan. We hope to see more future research on other cases and places in Japan that confirms or challenges our idea that the approach in Japan, especially the more recent CEE and CES concepts, which instantiate the values of care and cooperation, is primarily territorial oriented and the most meaningful for local circularity development.

Abbreviations CE: Circular economy; CEE: Circulating and ecological economy; CES: Circulating and ecological sphere; DCS: Dual circulation strategy; EMF: Ellen MacArthur Foundation; EU: European Union; FPSMCS: Fundamental Plan for a Sound Material-Cycle Society; METI: Ministry of Economy, Trade and Industry; NPO: Nonprofit organisation

Acknowledgements We want to acknowledge all the people, including interviewees in Onomichi, who shared their stories, observations and knowledge about circularity in Japan. This research was supported by the Ministry of Education, Culture, Sports, Science and Technology, Japan (MEXT). We want to thank the anonymous reviewers for their comments and all the people in Onomichi, Japan, for sharing their lived experiences of circularity. 
Author Contribution WW designed the study, collected, and analysed the data, and wrote the main part of the manuscript. MM identified additional concepts, wrote subsections of the first draft, and edited the draft.

Funding Open access funding provided by NTNU Norwegian University of Science and Technology (incl St. Olavs Hospital - Trondheim University Hospital). This research was supported by the Ministry of Education, Culture, Sports, Science and Technology, Japan (MEXT). Ministry of Education,Culture,Sports,Scien ce and Technology

Data Availability Interested people can send an email to the corresponding author to request access audio recorded interviews, transcripts, notes, and photographs.

\section{Declarations}

Ethics Approval and Consent to Participate Informed consent was obtained from all individual participants included in the study. All participants were adults.

Consent for Publication The authors give their consent for the publication of identifiable details, which can include photograph(s) and/or case history and/or details within the text ('Material') to be published in the above Journal and Article. The publishers have the right to publish the photographs, which are all taken by the first author.

Competing Interests The authors declare no competing interests.

Open Access This article is licensed under a Creative Commons Attribution 4.0 International License, which permits use, sharing, adaptation, distribution and reproduction in any medium or format, as long as you give appropriate credit to the original author(s) and the source, provide a link to the Creative Commons licence, and indicate if changes were made. The images or other third party material in this article are included in the article's Creative Commons licence, unless indicated otherwise in a credit line to the material. If material is not included in the article's Creative Commons licence and your intended use is not permitted by statutory regulation or exceeds the permitted use, you will need to obtain permission directly from the copyright holder. To view a copy of this licence, visit http://creativecommons.org/licenses/by/4.0/.

\section{References}

1. Prendeville S, Cherim E, Bocken N (2018) Circular cities: mapping six cities in transition. Environ Innov Soc Transit 26:171-194. https://doi.org/10.1016/j.eist.2017.03.002

2. Ghisellini P, Cialani C, Ulgiati S (2016) A review on circular economy: the expected transition to a balanced interplay of environmental and economic systems. J Clean Prod 114:11-32. https://doi.org/ 10.1016/j.jclepro.2015.09.007

3. Fratini CF, Georg S, Jørgensen MS (2019) Exploring circular economy imaginaries in European cities: a research agenda for the governance of urban sustainability transitions. J Clean Prod 228:974989. https://doi.org/10.1016/j.jclepro.2019.04.193

4. Tapia C, Bianchi M, Pallaske G, Bassi AM (2021) Towards a territorial definition of a circular economy: exploring the role of territorial factors in closed-loop systems. Eur Plan Stud 29(8):1438-1457. https://doi.org/10.1080/09654313.2020.1867511

5. Kirchherr J, Reike D, Hekkert M (2017) Conceptualizing the circular economy: an analysis of 114 definitions. Resour Conserv Recycl 127:221-232. https://doi.org/10.1016/j.resconrec.2017.09.005

6. Marin J, De Meulder B (2016) Antwerp City Wastescapes. Historic interplays between waste \& urban development. Int Plan Hist Soc Proc 17:179-190

7. Desrochers P (2001) Cities and industrial symbiosis: some historical perspectives and policy implications. J Ind Ecol 5:29-44. https://doi.org/10.1162/10881980160084024

8. Parkins E (1934) The geography of American geographers. Geogr J 33:221-230. https://doi.org/10. $1080 / 00221343408987396$

9. Simmonds PL (1862) Waste products and undeveloped substances. R. Hardwicke, London

10. Skene K, Murray A (2017) Sustainable economics: context, challenges and opportunities for the 21st century practitioner. Routledge, London 
11. Bocken NM, De Pauw I, Bakker C, Van Der Grinten B (2016) Product design and business model strategies for a circular economy. J Ind Prod Eng 33(5):308-320. https://doi.org/10.1080/21681015. 2016.1172124

12. Campbell-Johnston K, Cate JT, Elfering-Petrovic M, Gupta J (2019) City level circular transitions: barriers and limits in Amsterdam, Utrecht and The Hague. J Clean Prod 235:1232-1239. https://doi. org/10.1016/j.jclepro.2019.06.106

13. Williams J (2021) Circular cities: a revolution in urban sustainability. Routledge, London

14. Marin J, De Meulder B (2018) Interpreting circularity. circular city representations concealing transition drivers. Sustainability 10:1310. https://doi.org/10.3390/su10051310

15. Van den Berghe K, Vos M (2019) Circular area design or circular area functioning? A discourseinstitutional analysis of circular area developments in Amsterdam and Utrecht, the Netherlands. Sustainability 11:4875. https://doi.org/10.3390/su11184875

16. Geddes P (1925) The valley plan of civilization. Survey Graphi. 288.

17. Wall E (2021) Cities after landscape: post-landscapes, other practices, and all things. In: Contin A (ed) Metropolitan landscapes. Springer, Cham, pp 53-66

18. Welter VM (2014) The Valley Region: from figure of thought to figure on the ground. New Geogr 6:78-87

19. Magnaghi, A. (2005). The urban village: A charter for democracy and local self-sustainable development. Zed books.

20. Bauwens T (2021) Are the circular economy and economic growth compatible? A case for postgrowth circularity. Resour Conserv Recycl 175(August):105852. https://doi.org/10.1016/j.resco nrec.2021.105852

21. Caradonna J, Borowy I, Green T, Victor PA, Cohen M, Gow A, Heinberg R (2015) A degrowth response to an ecomodernist manifesto. Resilience. Org.

22. Genovese A, Pansera M (2020) The circular economy at a crossroads: technocratic eco-modernism or convivial technology for social revolution? Capital Nat Social:1-19. https://doi.org/10.2139/ ssrn.3459180

23. Moe J (2000) Basic act on establishing a sound material-cycle society. FAO, FAOLEX, Japan

24. Ogunmakinde OE (2019) A review of circular economy development models in China. Germany and Japan Recycling 4:27. https://doi.org/10.3390/recycling4030027

25. Snyder H (2019) Literature review as a research methodology: an overview and guidelines. J Bus Res 104:333-339. https://doi.org/10.1016/j.jbusres.2019.07.039

26. Pierce J, Lawhon M (2015) Walking as method: Toward methodological forthrightness and comparability in urban geographical research. Prof Geogr 67(4):655-662

27. Ozu Y. (1953) Tokyo Story [Youtube]. Japan: Shochiko.

28. Leipold S, Weldner K, Hohl M (2021) Do we need a 'circular society'? Competing narratives of the circular economy in the French food sector. Ecol Econ 187:107086. https://doi.org/10.1016/j. ecolecon.2021.107086

29. Korhonen J, Nuur C, Feldmann A, Birkie SE (2018) Circular economy as an essentially contested concept. J Clean Prod 175:544-552. https://doi.org/10.1016/j.jclepro.2017.12.111

30. Kovacic Z, Strand R, Völker T (2019) The circular economy in Europe: critical perspectives on policies and imaginaries. Routledge

31. Friant MC, Vermeulen WJV, Salomone R (2020) A typology of circular economy discourses: navigating the diverse visions of a contested paradigm. Resour Conserv Recycl 161:104917. https:// doi.org/10.1016/j.resconrec.2020.104917

32. Skene KR (2018) Circles, spirals, pyramids and cubes: why the circular economy cannot work. Sustain Sci 13(2):479-492

33. Millar N, McLaughlin E, Börger T (2019) The circular economy: swings and roundabouts? Ecol Econ 158:11-19

34. Adami L, Schiavon M (2021) From Circular Economy to Circular Ecology: A Review on the Solution of Environmental Problems through Circular Waste Management Approaches. Sustainability 13(2):925

35. Lazarevic D, Valve H (2017) Narrating expectations for the circular economy: towards a common and contested European transition. Energy Res Soc Sci 31:60-69. https://doi.org/10.1016/j.erss. 2017.05.006

36. Williams J (2019) Circular cities: Challenges to implementing looping actions. Sustainability 11(2):423

37. Arsova S, Genovese A, Ketikidis PH, Alberich JP, Solomon A (2021) Implementing regional circular economy policies: a proposed living constellation of stakeholders. Sustainability 13:4916. https://doi.org/10.3390/su13094916 
38. Heck P (2006) Circular economy related international practices and policy trends: current situation and practices on sustainable production and consumption and international Circular Economy development policy summary and analysis. World Bank Report

39. Van Berkel R, Fujita T, Hashimoto S, Geng Y (2009) Industrial and urban symbiosis in Japan: analysis of the Eco-Town program 1997-2006. J Environ Manag 90:1544-1556. https://doi.org/10. 1016/j.jenvman.2008.11.010

40. METI (2004) Handbook on resource recycling legislation and 3R initiatives. Japanese Ministry of Economy, Trade and Industry, Tokyo

41. Wang N, Lee JCK, Zhang J, Chen H, Li H (2018) Evaluation of Urban circular economy development: an empirical research of 40 cities in China. J Clean Prod 180:876-887. https://doi.org/10. 1016/j.jclepro.2018.01.089

42. McDowall W, Geng Y, Huang B, Barteková E, Bleischwitz R, Türkeli S, Kemp R, Doménech T (2017) Circular economy policies in China and Europe. J Ind Ecol 21:651-661. https://doi.org/10. $1111 /$ jiec. 12597

43. Guo B, Geng Y, Ren J, Zhu L, Liu Y, Sterr T (2017) Comparative assessment of circular economy development in China's four megacities: the case of Beijing, Chongqing, Shanghai and Urumqi. J Clean Prod 162:234-246. https://doi.org/10.1016/j.jclepro.2017.06.061

44. Mathews JA, Tan H (2016) Circular economy: lessons from China. Nature 531:440-442. https://doi. org/10.1038/531440a

45. Reike D, Vermeulen WJV, Witjes S (2018) The circular economy: new or Refurbished as CE 3.0? Exploring controversies in the conceptualization of the circular economy through a focus on history and resource value retention options. Resour Conserv Recycl 135:246-264. https://doi.org/10.1016/j. resconrec.2017.08.027

46. Levoso AS, Gasol CM, Martínez-Blanco J, Durany XG, Lehmann M, Gaya RF (2020) Methodological framework for the implementation of circular economy in urban systems. J Clean Prod 248:119227. https://doi.org/10.1016/j.jclepro.2019.119227

47. Wuyts W, Sedlitzky R, Morita M, Tanikawa H (2020) Understanding and managing vacant houses in support of a material stock-type society — the case of Kitakyushu. Japan Sustainability 12:5363. https://doi.org/10.3390/su12135363

48. Dagilienè L, Varaniūtė V, Bruneckienè J (2021) Local governments' perspective on implementing the circular economy: a framework for future solutions. J Clean Prod 310:127340. https://doi.org/10. 1016/j.jclepro.2021.127340

49. Papageorgiou A, Henrysson M, Nuur C, Sinha R, Sundberg C, Vanhuyse F (2021) Mapping and assessing indicator-based frameworks for monitoring circular economy development at the city-level. Sustain Cities Soc 75:103378. https://doi.org/10.1016/j.scs.2021.103378

50. Marin J, Alaerts L, Van Acker K (2020) A materials bank for circular leuven: how to monitor 'messy' circular city transition projects. Sustainability 12:10351. https://doi.org/10.3390/su122410351

51. Veyssière S, Laperche B, Blanquart C (2021) Territorial development process based on the circular economy: a systematic literature review. Eur Plan Stud:1-20. https://doi.org/10.1080/09654313.2021. 1873917

52. Chembessi C, Beaurain C, Cloutier G (2021) Building territorial value within local circular economy's projects: lessons from French scholars' studies. Local Environ 26:1145-1151. https://doi.org/10. $1080 / 13549839.2021 .1964458$

53. Geddes P (1904) Civics: as applied sociology, Part I. Sociol Pap 105https://doi.org/10.1177/00380 26104SP100110

54. Geddes P (1915) Cities in evolution. Williams and Norgate, London

55. von Humboldt A (1997) Cosmos: a sketch of the physical description of the universe, trans. Johns Hopkins University Press, Baltimore, MD, E.C. Otté

56. Bauwens T, Hekkert MP, Kirchherr J (2020) Circular futures: what will they look like? Ecol Econ 175:106703. https://doi.org/10.1016/j.ecolecon.2020.106703

57. Khmara Y, Kronenberg J (2018) Degrowth in business: an oxymoron or a viable business model for sustainability? J Clean Prod 177:721-731. https://doi.org/10.1016/j.jclepro.2017.12.182

58. Friedmann J (1996) Modular cities: beyond the rural-urban divide. Environ Urban 8:129-131. https:// doi.org/10.1630/095624796322752975

59. Magnaghi A (2020) The territorialist approach to urban bioregions. In: Fanfani D, Ruiz AM (eds) Bioregional planning and design, vol I. Springer, Cham, pp 33-36

60. Magnaghi A (2010) Draft of the territorialists' society manifesto. Translated by Marie-Anne Gillis. Accessed on 17 December 2021. http://www.societadeiterritorialisti.it/wp-content/uploads/2013/05/ 110221b_draft.of.the.territorialists.society.manifesto.pdf 
61. Paiho S, Mäki E, Wessberg N, Paavola M, Tuominen P, Antikainen M, Heikkilä J, Rozado CA, Jung N (2020) Towards circular cities-Conceptualizing core aspects. Sustain Cities Soc 59:102143. https://doi.org/10.1016/j.scs.2020.102143

62. Vanhuyse F, Fejzić E, Ddiba D, Henrysson M (2021) The lack of social impact considerations in transitioning towards urban circular economies: a scoping review. Sustain Cities Soc 75:103394. https:// doi.org/10.1016/j.scs.2021.103394

63. Kębłowski W, Lambert D, Bassens D (2020) Circular economy and the city: an urban political economy agenda. Cult Organ 26:142-158. https://doi.org/10.1080/14759551.2020.1718148

64. Swyngedouw E, Heynen NC (2003) Urban political ecology, justice and the politics of scale. Antipode 35:898-918. https://doi.org/10.1111/j.1467-8330.2003.00364.x

65. Hermann RR, Pansera M, Cívica P (2020) Contingencies of circular economy: discourse hegemony and institutionalization in Norway. SSRN Electron J. https://doi.org/10.2139/ssrn.3690601

66. Tsui T, Peck D, Geldermans B, van Timmeren A (2020) The role of urban manufacturing for a circular economy in cities. Sustainability 13:23. https://doi.org/10.3390/su13010023

67. Anguelovski I (2016) From toxic sites to parks as (green) LULUs? New challenges of inequity, privilege, gentrification, and exclusion for urban environmental justice. J Plan Lit 31:23-36. https://doi. org/10.1177/0885412215610491

68. Curran W, Hamilton T (2017) Just green enough: urban development and environmental gentrification. Routledge, New York

69. Wolch JR, Byrne J, Newell JP (2014) Urban green space, public health, and environmental justice: the challenge of making cities 'just green enough.' Landsc Urban Plan 125:234-244. https://doi.org/10. 1016/j.landurbplan.2014.01.017

70. Girardet H (1996) Cities: new directions for sustainable urban living. Gaia Books, London

71. Brown A (2013) Just enough: lessons in living green from traditional Japan. Tuttle Publishing, North Clarendon

72. Barles S (2014) History of waste management and the social and cultural representations of waste. In: Agnoletti M, Serneri SN (eds) The basic environmental history. Springer, Cham, pp 199-226

73. Takeuchi K (2010) Rebuilding the relationship between people and nature: the Satoyama initiative. Ecol Res 25:891-897. https://doi.org/10.1007/s11284-010-0745-8

74. Takeuchi K, Ichikawa K, Elmqvist T (2016) Satoyama landscape as social-ecological system: historical changes and future perspective. Curr Opin Environ Sustain 19:30-39. https://doi.org/10.1016/j. cosust.2015.11.001

75. Tanaka M (1999) Recent trends in recycling activities and waste management in Japan. J Mater Cycles Waste Manag 1:10-16

76. Solarcrew (2021) Solar crew. https://solarcrew.jp/. Accessed 30 June 2021

77. Yokohama City (2021) SDGs future city. https://www.city.yokohama.lg.jp/kurashi/machizukuri-kankyo/ondanka/futurecity/sdgs/sdgsfuturecity.files/0033_20190424.pdf. Accessed June 2021

78. Yoshida F, Hata A, Tonegawa H (1999) Itai-Itai disease and the countermeasures against cadmium pollution by the Kamioka mine. Environ Econ Policy Stud 2:215-229. https://doi.org/10.1007/bf033 53912

79. Irvine S, Bai X (2019) Positive inertia and proactive influencing towards sustainability: systems analysis of a frontrunner city. Urban Transform 1:1-27. https://doi.org/10.1186/s42854-019-0001-7

80. Japan MOE (1970) Waste management and public cleansing law (Law No. 137). Tokyo, Japan

81. Takeuchi K (2019) Circulating and ecological economy--regional and local ces: an IGES proposal. Institute for Global Environmental Strategies. Institute for Global Environmental Strategies, Japan.

82. Van den Berghe K, BucciAncapi F, van Bueren E (2020) When a fire starts to burn. The relation between an (inter)nationally oriented incinerator capacity and the port cities' local circular ambitions. Sustainability 12:4889. https://doi.org/10.3390/su12124889

83. Scheyvens H, Mader A, Lopez-Casero F, Takahashi Y (2019) Socio-ecological production landscapes and seascapes as regional/local circulating and ecological spheres. Institute for Global Environmental Strategies, Japan.

84. Morioka T, Tsunemi K, Yamamoto Y, Yabar H, Yoshida N (2005) Eco-efficiency of advanced loopclosing systems for vehicles and household appliances in Hyogo Eco-town. J Ind Ecol 9:205-221. https://doi.org/10.1162/108819805775247909

85. Moriguchi Y (2007) Material flow indicators to measure progress toward a sound material-cycle society. J Mater Cycles Waste Manag 9:112-120. https://doi.org/10.1007/s10163-007-0182-0

86. McCurry J (2020) 'No-waste' Japanese village is a peek into carbon-neutral future, The Guardian. https://www.theguardian.com/world/2020/mar/20/no-waste-japanese-village-is-a-peek-into-carbonneutral-future. Accessed 31 August 2021 
87. METI (2021) Guidance for disclosure and engagement for promoting sustainable finance toward a circular economy. https://www.meti.go.jp/english/press/2021/pdf/0119_004b.pdf. Accessed August 2021

88. Ortiz-Moya F, Kataoka Y, Saito O, Mitra BK, Takeuchi K (2021) Sustainable transitions towards a resilient and decentralised future: Japan's Circulating and Ecological Sphere (CES). Sustain Sci 16:1717-1729. https://doi.org/10.1007/s11625-021-00941-y

89. Hotta Y, Akenji L, Aoki-Suzuki C, Watabe A, Liu C, Nakatani J, Kurisu K, Amasawa E (2019) Six proposals for future policies towards circular economy and society. Asian Development Bank Institute

90. Thapa K, Sukhwani V, Deshkar S, Shaw R, Mitra BK (2020) Strengthening urban-rural resource flow through regional circular and ecological sphere (R-CES) approach in Nagpur. India Sustainability 12:8663. https://doi.org/10.3390/su12208663

91. Circular Yokohama (2021) Kanazawa Living Lab. https://circular.yokohama/en/projects/kanazawaliving-lab/. Accessed June 2021

92. METI (2020) Circular economy vision 2020 compiled. https://www.meti.go.jp/english/press/2020/ 0522_003.html. Accessed August 2021

93. Döringer S, Uchiyama Y, Penker M, Kohsaka R (2020) A meta-analysis of shrinking cities in Europe and Japan. Towards an integrative research agenda. Eur Plan Stud 28:1693-1712. https://doi.org/10. $1080 / 09654313.2019 .1604635$

94. Kubo T, Yui Y (2020) The rise in vacant housing in post-growth Japan. Springer Singapore, Singapore

95. Amenta L, van Timmeren A (2018) Beyond wastescapes: towards circular landscapes. Addressing the spatial dimension of circularity through the regeneration of wastescapes. Sustainability 10:4740. https://doi.org/10.3390/su10124740

96. Godschalk DR (2004) Land use planning challenges: coping with conflicts in visions of sustainable development and livable communities. J Am Plan Assoc 70:5-13. https://doi.org/10.1080/01944 360408976334

97. Waswo A (2013) Housing in postwar Japan - a social history. Routledge, London

98. Kikusawa I, Kondo K (2017) Designing autonomous communities in suburbs of Japan. Eur J Sustain Dev 6:1-10. https://doi.org/10.14207/ejsd.2017.v6n1p1

99. Kubo T, Mashita M (2020) Why the rise in urban housing vacancies occurred and matters in Japan. In: Kubo T, Yui Y (eds) The rise in vacant housing in post-growth Japan. Springer, Singapore, pp 3-22

100. Marin J, De Meulder B (2021) Time is life. Ruimte:22-25. https://doi.org/10.1080/13264826.2021. 1973049

101. Kubo T (2020) Divided Tokyo: housing policy, the ideology of homeownership, and the growing contrast between the city center and the suburbs. Divid Tokyo 11:21-46. https://doi.org/10.1007/ 978-981-15-4202-2_2

102. Harding R (2015) Is this the solution to Japan's glut of empty homes. Financial Times, Jul, 17

103. Leishman F (1994) Under Western eyes: perspectives on policing and society in Japan. Polic Soc 4:35-51. https://doi.org/10.1080/10439463.1994.9964681

104. Hiwasaki L (2006) Community-based tourism: a pathway to sustainability for Japan's protected areas. Soc Nat Resour 19:675-692. https://doi.org/10.1080/08941920600801090

105. Filho W, Echevarria L, Neht A, Klavins M, Morgan E (2018) Coping with the impacts of urban heat Islands a literature based study on understanding urban heat vulnerability and the need for resilience in cities in a global climate change context. J Clean Prod 171:1140-1149. https://doi.org/10.1016/j. jclepro.2017.10.086

106. Haraway D (2018) Staying with the trouble for multispecies environmental justice. Dialogues Hum Geogr 8:102-105. https://doi.org/10.1177/2043820617739208

107. Escobar A (2018) Designs for the pluriverse. Duke University Press, Durham

108. Avrami E (2016) Making historic preservation sustainable. J Am Plan Assoc 82:104-112. https://doi. org/10.1080/01944363.2015.1126196

109. Circular Yokohama (2020) Accelerating the circular economy in Yokohama. https://circular.yokoh ama/en/. Accessed 30 June 2021

110. Marin J, De Meulder B (2018) Urban landscape design exercises in urban metabolism: reconnecting with Central Limburg's regenerative resource landscape. J Landsc Archit 13:36-49. https://doi.org/ 10.1080/18626033.2018.1476031

111. Zero Waste Scotland (2020) Circular highlands and Islands. https://www.zerowastescotland.org.uk/ content/circular-highlands-and-islands._Accessed 31 August 2021 
112. Lin Justin Yifu \& Xiaobing Wang (2021) Dual Circulation: a New Structural Economics view of development. Journal of Chinese Economic and Business Studies. https://doi.org/10.1080/14765284. 2021.1929793

113. Javed, S. A., Bo, Y., Tao, L., \& Dong, W. (2021). The 'Dual Circulation'development model of China: Background and insights. Rajagiri Management Journal.

114. Nikulina V, Lindal JL, Baumann H, Simon D, Ny H (2019) Lost in translation: A framework for analysing complexity of co-production settings in relation to epistemic communities, linguistic diversities and culture. Futures 113:102442. https://doi.org/10.1016/j.futures.2019.102442

115. Hayashi A (2002) Finding the voice of Japanese wilderness. Int J Wilderness 8:34-37 